\title{
NUMERICAL SIMULATIONS ON THE EFFECT OF OVER-FIRE AIR TO THE COMBUSTION PERFORMANCE IN A 2950 T/H TANGENTIAL-FIRED BOILER
}

\author{
Guozhen SHAO*, Jianwen ZHANG*, Gongquan LIU*, Tao REN**, \\ Ziyu LIAO**, Dongbo SI**, Kefa CEN**, Hao ZHOU** \\ * Shanghai boiler Works Ltd, Shanghai, P.R.C \\ ** State Key Laboratory of Clean Energy Utilization, Zhejiang University, Hangzhou, P.R.C
}

\begin{abstract}
MWe}$ capacity super critical utility units, which employs the low NOx concentric firing system (LNCFS) and the deep air staged technology for reduce the NOx emission. In this work, the comparison of two schemes of separated over-fire-air employment was conducted using the numerical simulation method, the flow field, temperature distribution, oxygen concentration in the furnace and NOx emission were obtained. The numerical results showed that the combustion system employed in the $2950 \mathrm{t} / \mathrm{h}$ tangential-fired boiler had good performance on the NOx reduction, carbon burnout. The NOx emission can be reduced to less than $300 \mathrm{mg} / \mathrm{Nm}^{3}$ when the Shenhua coal was burned.
\end{abstract}

Keywords: Numerical, 1000MWe boiler, Over-fire-air, LNCFS

\section{INTRODUCTION}

Nitrogen oxides emissions from the large combustion system, such as: utility boilers, is a relevant problem due to their harmful impact on the environment. The supercritical units or ultra supercritical units with high efficiency and low emission are the future trend of the fossil power plant in China because of their potential in reduction of nitrogen oxides. Large size pulverized-coal-fired utility boilers develop rapidly in China, both their reliability and economics have reached better level. Ultra-large scale single furnace bi-tangential circle utility boilers, with the low NOx concentric firing system (LNCFS) perform well on reducing NOx emission.

In this work, numerical simulation was applied to simulate the turbulent flow, coal combustion and NOx formation process in the furnace.

\section{BOILER IN RESEARCH}

\subsection{Structure of Boiler}

The furnace in this work was a ultra-

supercritical single furnace bi-tangential circle, once intermediate reheat, balanced ventilation, solid state slag-tap, steel suspension structure $\Pi$ type $1000 \mathrm{MWe}$ boiler. Shenhua coal was designed to burn in the furnace. Coal pulverizing system was a medium speed pressurized direct pulverizing coal systems.

\subsection{Features}

1. Both the spirally water wall and Vertical Water Wall were arranged in the furnace and the arrangement could meet the requirement of variable pressure operation. Owing to the larger furnace section and volume, the thermal load of the furnace cross-section and the outlet flue gas temperature are lower.

2. In the single furnace bi-tangential circle boiler, two combustion systems perform, of which the air volume and powder content are easier to control. Compared to the single tangential circle furnace, boiler capacity of bi-tangential circle arrangement mode decrease to half and the flue gas temperature deviation of the furnace outlet is reduced. Meanwhile, bi-tangential circle firing system contains the advantages of the single tangential circle firing system such as: high combustion efficiency, low Nox emission, lower peak heat flux and mean temperature of flue gas, distribution of the furnace dsc curve has nothing to do with the number of the fuel layers and so on.

3. The low Nox concentric firing system (LNCFS) is applied to reduce NOx emission. With the help of the LNCFS system, low stable combustion load without oil is improved and the combustion efficiency increases. In addition, the LNCFS system has the effect of preventing slagging in furnace and high temperature together with the efficiency of lowering the flue gas temperature deviation of furnace outlet. The LNCFS system in the early stage of combustion, when the volatile nitrogen starts to form, reduces the oxygen content. It combines the sectionalized combustion in the whole furnace and the sectionalized combustion in some partial area to reduce NOx. In the initial fuel-rich case, it urges the transformation from volatile nitrogen to nitrogen gas, which achieves the goal of reducing the NOx.

4. The main 2components of LNCFS system:
a. CCOFA
b. SOFA
c.CFS
d. EI

\section{DESIGNED CASES}

Two different design cases were applied in our work. The main distinction between the two cases was the layer numbers of the SOFA, while the total air volume into the furnace and coal feed are the same. In the second case, separate over-fire-air volume decreased and the equal distribution of the reduced air volume was added to the

Copyright (C) 2009 by the Japan Society of Mechanical Engineering 
secondary air of the primary combustion zone. The air distribution of the modeling cases is shown in Table.1.

Table1 Air Distribution of Modeling Cases

\begin{tabular}{cccccc}
\hline & $\begin{array}{c}\text { SOFA } \\
\text { Layer } \\
\text { Num. }\end{array}$ & $\begin{array}{c}\text { Primary } \\
\text { air } \\
(\%)\end{array}$ & $\begin{array}{c}\text { Fuel } \\
\text { air } \\
(\%)\end{array}$ & CFS & SOFA \\
& $(\%)$ & $(\%)$ \\
\hline Case1 & 5 & 22 & 5.6 & 41.2 & 31.1 \\
Case2 & 3 & 22 & 5.6 & 53.7 & 18.7 \\
\hline
\end{tabular}

\section{MATHEMATICAL MODEL}

\subsection{Coupling Between Gas Phase and Particle Phase}

When the pulverized coal is injected into the furnace, it is heated by the high temperature airflow. And then the volatile precipitates that the coal combusts. At last, the coke catches fire. Gas-solid two-phase flow in the furnace is lean phase flow while the collision between particles can be ignored. Lagrangian method is applied to investigate the motion of pulverized coal particles, which is more convenient to model the motion and combustion process of single coal particle. The PSIC ${ }^{[1-3]}$ (Particle source in cell) is used to couple between the two phases. The main idea is to solve the momentum and energy equations according to the features of the gas phase in the furnace and meanwhile calculate the mass loss of coal particles because of volatilization and oxidation. And then the mass, momentum and energy conversions are calculated according to the results of particulate phase which are used as a source to implement the coupling between two phases.

\subsection{Particulate Governing Equations ${ }^{[4-5]}$}

a. mass equation:

$$
\frac{d m_{p}}{d t}=-r_{p}
$$

$r_{p}=r_{v}+r_{h l}$, where $r_{v}$ and $r_{h l}$ are the mass loss because of the precipitation of volatile and the oxidation of coke respectively.

b. momentum equations:

$$
m_{p} \frac{d \vec{v}_{p}}{d t}=\bar{F}
$$

The force item $\vec{F}$ contains: steady gas friction, buoyancy, imaginary mass force, Basset force, Magnus force, Saffman lift force, thermophoresis force and the force created by the inhomogeneity of the face of mass flow during the reaction. Except for the gas friction, other forces can be neglected. Taking the $\mathrm{x}$ direction for example:

$m_{p} \frac{d u_{p}}{d t}=m_{p} F_{D}\left(u-u_{p}\right)+m_{p} \frac{g_{x}\left(\rho_{p}-\rho\right)}{\rho_{p}}+m_{p} F_{x}$

Where $m_{p} F_{D}\left(u-u_{p}\right)$ is the gas friction per unit mass, $u$ and $u_{p}$ for the velocity of gas and particle respective.

$$
F_{D}=\frac{18}{\rho_{p} d_{p}^{2}} \frac{C_{D} R_{e}}{24} \text {, where } C_{D} \text { is the }
$$

resistance coefficient, $R_{e}$ is the relative Reynolds number $\left(R_{e}=\frac{\rho d_{p}\left|u-u_{p}\right|}{\mu}\right), \mu$ and $d_{p}$ are the gaseous viscosity and diameter of particle. $m_{p} \frac{g_{x}\left(\rho_{p}-\rho\right)}{\rho_{p}}$ denotes the resultant force of gravity and gas phase buoyancy, $\rho$ and $\rho_{p}$ for density of gas and particle while $m_{p}$ is for weight of particle. $F_{x}$ denote the other resultant force at the $\mathrm{x}$ direction.

c. energy equations:

$$
m_{p} \frac{d h_{p}}{d t}=Q_{c o n}+Q_{r a d}+Q_{v}+Q_{h}
$$

$Q_{\text {con }}, Q_{\text {rad }}, Q_{v}$ and $Q_{h}$ denote the convective heat transfer, radiation heat transfer, pyrolytic sublimation heat and coke oxidation reaction heat.

d. locus equation:

$$
\frac{d s}{d t}=u_{p}
$$

\subsection{Particulate Reaction Models}

The volatile precipitation model and coke combustion model are introduced to describe the combustion process. ${ }^{[3,6-7]}$

a. volatile precipitation model of raw coal

When the particle is heated to some temperature threshold value, the volatile begins to precipitate. In our work, Competitive two-step reaction two-equation model is employed.

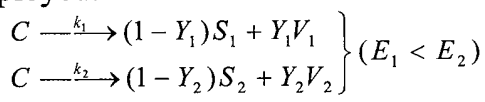

b. reaction rate equation:

$$
\frac{d v}{d t}=\frac{d v_{1}+d v_{2}}{d t}+\left(Y_{1} K_{1}+Y_{2} K_{2}\right) c
$$

Where $K_{1}$ and $K_{2}$ are Arrhenius reaction rate coefficient, chemical equivalent parameter $Y_{1}$ and $Y_{2}$ can be estimated by the percentage of the volatile in the industrial analysis and the volatile during high temperature. The model can stimulate the volatile precipitation with temperature change.

b. The heterogeneous oxidation model of residual coke:

When the volatile completely precipitates, the coke begins to combust and then the dynamic model and diffusion reaction rate model are employed.

Diffusion rate constant:

$$
D_{0}=C_{1} \frac{\left[\left(T_{p}+T_{\infty}\right) / 2\right]^{0.75}}{d_{p}}
$$

Chemical kinetic constant: $R=C_{2} e^{-\left(E / R T_{p}\right)} \quad()$

The combustion rate of coke obtained by the upper two constants:

$$
\frac{d m_{p}}{d t}=-\pi d_{p}^{2} P_{o x} \frac{D_{0} R}{D_{0}+R}
$$

Where $P_{o x}$ is the partial pressure of the gas surrounding the particle, $R$ is the chemical kinetic constant considering the diffusion and reaction of inner surface of coke.

\section{RESULTS}

\subsection{Temperature Distribution}

According to temperature distribution at section of the primary air and CFS jets, combustion cases in the furnace are good. The two tangential circle combustion systems do not disturb each other, each shows the features of single tangential circle combustion systems. Temperature field and 
velocity field of nearly symmetric distribution are formed, which denotes that the current arrangement of burners has a reasonable depth to width ratio of working points.
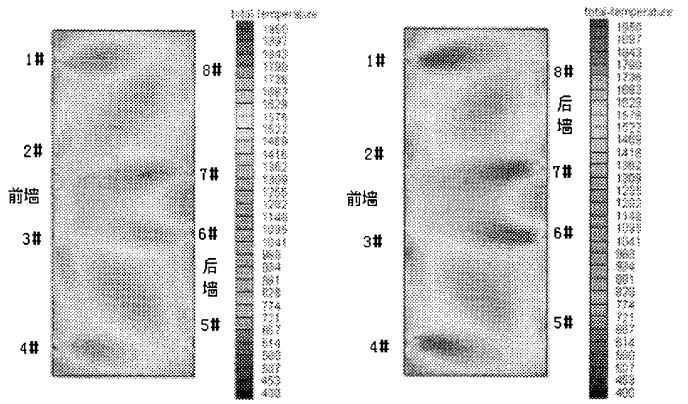

Figure.1. Temperature distribution of primary air and CFS nozzle section (case1)

As shown in figure.1, ignition distance of primary air is shorter, the pulverized coal is heated to the ignition temperature and starts to combust, forming the high temperature coal powder torch. The tangential circle of temperature is larger, coincides with the tangential circle of velocity. When the CFS with prearranged declination is applied, because of the traction between air flows, all the circles are larger and deflect a bit to the direction of rotation. The two circles intersect with each other at the corner2 and corner 3 of central front wall and form the high load local area.
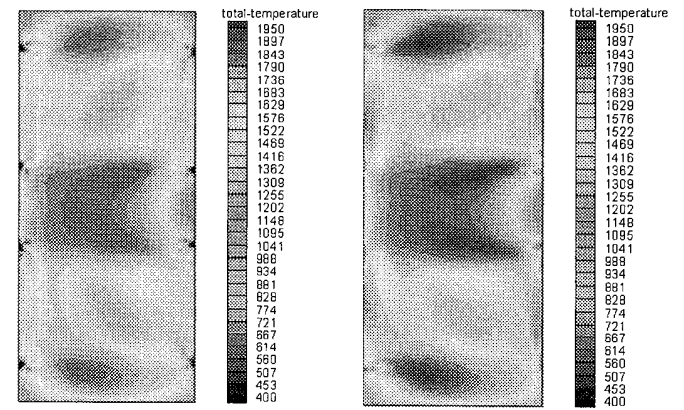

Figure.2. Temperature distribution of primary air and CFS nozzle section (case2)

Compared to the temperature distribution of case1, it can be directly seen that the high temperature areas at nozzle section of each layer in primary combustion zone get larger in case 2 .

\subsection{Oxygen Content Distribution}

According to the oxygen content distribution at the nozzle section of secondary air in figure.3,

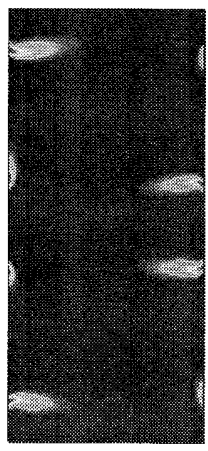

Case 1

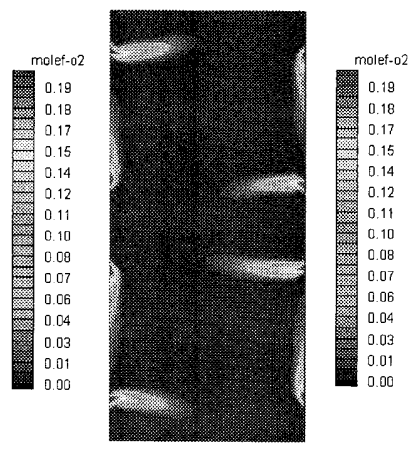

Case2
Figure.3. Oxygen distribution of secondary air nozzle section (case1)

the oxygen distributions at the two cases are similar. Owing to the low oxygen combustion in the primary combustion zone, except for the injection zone, the oxygen content at different sections is low which efficiently inhibit the formation of NOx. In the zone between the CCOFA and SOFA, because of the continuing of combustion, without feeding of oxygen, the zone near the water walls is hypoxic case, shown in Figure.4.

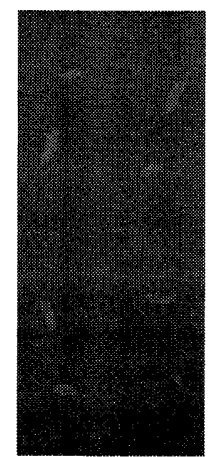

Case 1

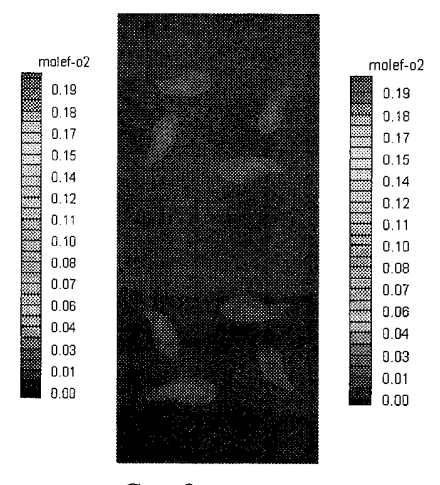

Case2
Figure.4. Oxygen distribution of $Z=28.5$ section (case1)

Compared to the case 1 , oxygen in primary combustion zone of case 2 has higher mole fraction while peak value of mole fraction in SOFA zone decreases from 2.5 to 2 . The distribution of oxygen in case 2 is more uniform in the furnace.

\section{3 $\mathrm{CO}_{2}$ and $\mathrm{CO}$ Distribution}

The two operating cases show the similar distribution regularity, in Figure.5.

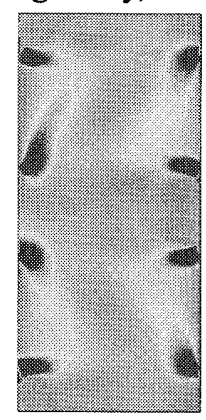

Case1

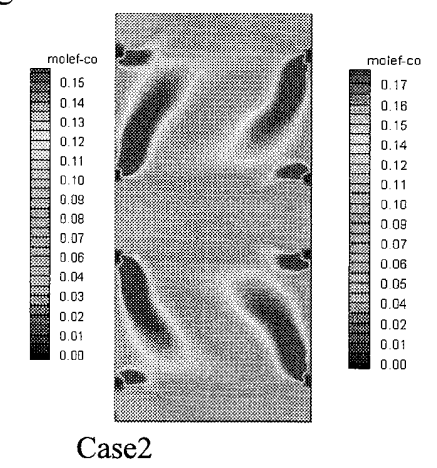

Case2
Figure.5. CO distribution of primary air section

In the injection zone of pulverized coal spray nozzle, the coal powder concentration is high, large quality of $\mathrm{CO}$ is formed.

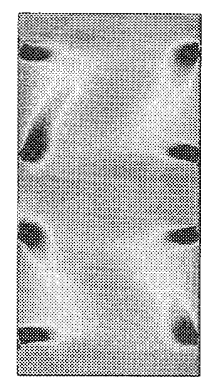

Case 1
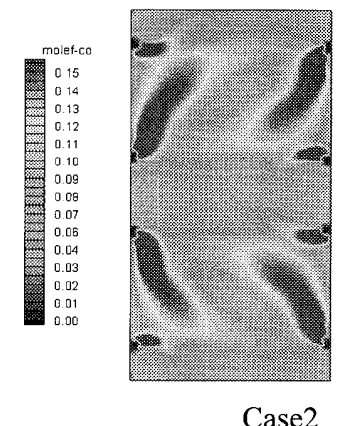

Case2

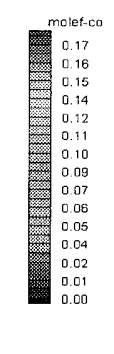


Figure.6. CO distribution of CFS air section

Figure. 6 clearly shows the feature of horizontal radial air staged combustion. In the medial side of the tangential circle of air flow, oxygen content for combustion is not immediately fed, the fraction of $\mathrm{CO}$ is high. $\mathrm{CO}_{2}$ mainly distributes at the zone of enough oxygen and the area with low particle concentration, such as near the water walls and the zone between two circles. The $\mathrm{CO}_{2}$ concentration is also high in the central zone of the circles, while the $\mathrm{CO}$ is low. Besides, owing to the integral axial stages in the furnace, in the two operating cases the integral concentration of $\mathrm{CO}$ is high.

\subsection{The Prediction of NO formation}

In accordance with the calculated results of the two operating case, most of the NO is formed at the nozzle outlet and the downstream area. The fraction of NO in the primary combustion zone is low which indicates the efficiency of low oxygen combustion as shown in Figure.7.

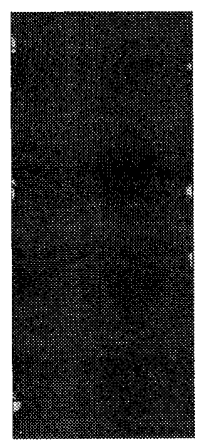

Primary air section

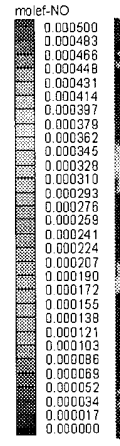

Figure.

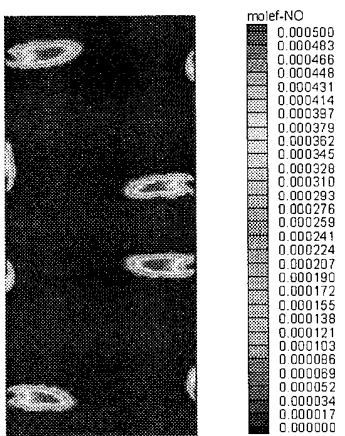

Secondary air section

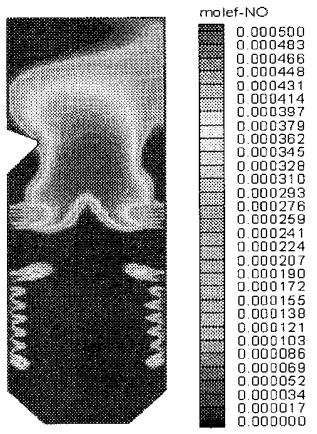

Case 1

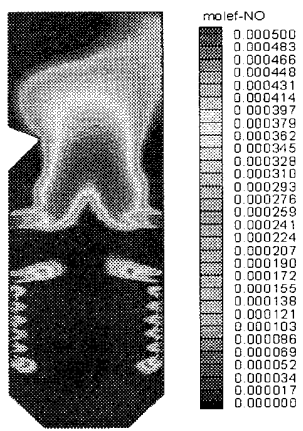

Case2
Figure.8. NO distribution of vertical diagonal section

At the area between primary combustion zone and SOFA zone, the friction of NO is low. Until to the SOFA section, high concentration range of NO occurs, as shown in Figure.8.

\section{CONCLUSION}

The numerical simulation of two designed operating cases for $1000 \mathrm{MW}$ utility boiler indicates that in single furnace bi-tangential circle combustion system, two opposite rotated tangential circle combustion zone without interference are formed. Corresponding temperature, velocity and components distribution show the bilateral symmetry feature.

This design not only contains the advantage of high efficiency, but also the uniform aerodynamic field and distribution of thermal load are obtained.

The designed LNCFS combustion system contains the biased secondary air and staged SOFA which can reduce the NOx emission significantly. The prediction of NOx emission is below $300 \mathrm{mg} / \mathrm{Nm}^{3}$ (Converted to $6 \%$ Oxygen), the NOx emission of case 2 is lower. Staged air combustion may affect the burn-out rate. According to the simulated results, in the two cases the heat loss of incomplete combustion is not much and the burn-out rate of case 2 is higher than case 2 significantly. From the comparison the two cases, we have a conclusion that the optimization of air distribution mode can realize the optimum combination of low NOx emission and high burn-out rate.

\section{ACKNOWLEDGEMENTS}

This work was supported by Zhejiang Provincial Natural Science Foundation of China (R107532), Program for New Century Excellent Talents in University (NCET-07-0761), a Foundation for the Author of National Excellent Doctoral Dissertation of China (200747) and Zhejiang University K.P.Chao's High Technology Development Foundation (2008RC001), National Basic Research Program of China (2009CB219802).

\section{REFERENCES}

[1] Weibiao $\mathrm{Fu}$, Coal combustion theory and its universal macro-laws (In Chinese), (2003) Tsinghua University Press, Beijing.

[2] Kefa Cen and Jianren Fan, Theory and calculations of engineering Gas-solid multiphase flow (In Chinese), (1990) Zhejiang University Press, Hangzhou.

[3] Jianxing Zhao, Numerical Simulation of Combustion (In Chinese), (2002), Tsinghua University Press, Beijing.

[4] Hao Zhou. Investigation on NOx Control and Combustion Optimization for Large Capacity Utility Boilers (In Chinese), Ph.D. thesis, (2004), Zhejiang University, Hangzhou.

[5] Xiangjun Liu. Numerical simulation of combustion processes in Tangentially Fired Pulverized Coal Boiler (In Chinese), (1997), Tsinghua University, Beijing.

[6] Yingshi Wang, Weicheng Fan, Lixing Zhou, Xuchang Xu. Numerical Calculation of the combustion process. (In Chinese), (1986), Science Press, Beijing.

[7] Spalding D B. Concentration fluctuations in a round turbulent free jet. Chemical Engineering Science, 11(2) (1985), pp.119-192. 